\title{
Treatment with interleukin-2 in malignant pleural mesothelioma: immunological and angiogenetic assessment and prognostic
} impact

\author{
G Ali', L Boldrini', M Lucchi ${ }^{2}$, A Picchi ${ }^{2}$, M Dell'Omodarme ${ }^{3}$, MC Prati $^{3}$, A Mussi $^{2}$, V Corsi ${ }^{1}$ and G Fontanini*, \\ 'Division of Pathological Anatomy, Department of Surgery, University of Pisa, Via Roma 57, Pisa 56 I 26, Italy; ${ }^{2}$ Division of Thoracic Surgery, Department of \\ Cardio-Thoracic Surgery, University of Pisa, Via Paradisa, Pisa 56 /4, Italy; ${ }^{3}$ Scuola Normale Superiore and Istituto di Fisica Nucleare, Section of Pisa, Pisa \\ 56126 , Italy
}

\begin{abstract}
BACKGROUND: Administration of interleukin-2 (IL-2) has shown some effects on malignant pleural mesothelioma (MPM) tumour regression. The purpose of this study was to investigate the ability of IL-2 to modify immunological effector cells and angiogenesis in MPM patients and their prognostic value.

METHODS: Tumour-infiltrating lymphocytes (CD4, CD8, Foxp3), mast cells (MCs) (tryptase and chymase), microvessel count (MVC) and VEGF were determined by immunohistochemistry in two series of MPM patients: 60 patients treated with intra-pleural preoperative IL-2 and 33 patients untreated.

RESULTS: Tryptase MCs, and CD8 and Foxp3 lymphocytes were significantly increased in the IL-2-treated group, whereas MVC was significantly lower in the same group. Moreover, in the IL-2-treated group, greater tryptase + MCs and greater Foxp3 lymphocytes were associated with improved and poorer clinical outcomes, respectively. Notably, when these two immunological parameters were combined, they predicted outcomes more effectively.

CONCLUSIONS: This study showed that IL-2 treatment leads to a significant increase of immunological parameters, concomitantly with a reduction in vasculature, providing new insight into the cancer mechanisms mediated by IL-2. Moreover, these results suggest that tryptase-positive MCs and Foxp3 + lymphocytes predict clinical outcomes in IL-2-treated patients, highlighting the critical role of the inflammatory response in mesothelioma cancer progression.

British Journal of Cancer (2009) I 01, 1869 - 1875. doi: 10.1038/sj.bjc.6605438 www.bjcancer.com

(c) 2009 Cancer Research UK
\end{abstract}

Keywords: malignant pleural mesothelioma; tumour microenvironment; interleukin-2; prognosis

Malignant pleural mesothelioma (MPM) is a relatively rare tumour with a growing occurrence in the past few decades throughout the world. It is a fatal neoplasm, with a median survival of 12 months in patients receiving palliative care (Robinson et al, 2005). Presently, there is no satisfactory treatment of MPM, although recent reports suggest that multimodality therapy, including surgery, may result in a significant improvement in the survival of select patients (Rusch et al, 2001; Lucchi et al, 2007).

The precise relationship between the immune system and cancer is still unknown. The tumour - host interaction has a pivotal role in tumour progression and involves various cell types present in the tumour microenvironment, including neoplastic cells, immune effector cells, stromal cells and extracellular matrix components (Zou, 2005). The tumour inflammatory infiltrate is composed of different immune effector cells, such as lymphocytes, macrophages, dendritic cells, and mast cells (MCs) (Balkwill and Mantovani, 2001). Particularly, tumour-infiltrating lymphocytes (TILs) present in the tumour microenvironment have been

*Correspondence: Professor G Fontanini;

E-mail: g.fontanini@med.unipi.it

Revised 30 September 2009; accepted 19 October 2009 recognised as principal effectors in modulating tumour immunity (Curiel et al, 2004; Yu and Fu, 2006).

Various studies have shown mesothelioma to be sensitive to immunotherapy using cytokines in an attempt to stimulate the anti-tumoural immune response (Robinson et al, 2005).

Interleukin-2 (IL-2) was first described as a pro-inflammatory cytokine produced by activated $\mathrm{T}$ cells whose main action is to promote proliferation, survival and differentiation of $\mathrm{T}$ cells (Cantrell and Smith, 1984; Rubin, 1993; Akbar et al, 1996; Armstrong et al, 2001). Intravenous, subcutaneous or intra-pleural administration of IL-2 has shown some effects on tumour regression in MPM, supporting the use of IL-2 in clinical trial settings (Goey et al, 1995; Astoul et al, 1998; Castagneto et al, 2001; Mulatero et al, 2001; Lucchi et al, 2007). However, the mechanism underlying the biological effects of IL-2 on tumour growth is complex and it is still largely unknown.

Interleukin-2 can affect many different cell types, particularly cytotoxic CD8 $+\mathrm{T}$ lymphocytes and regulatory $\mathrm{T}$ (Treg) cells. The latter cells are a subset of CD4 $+\mathrm{T}$ lymphocytes defined by their constitutive expression of the IL-2 receptor $\alpha$ chain CD25 (Sakaguchi et al, 1996). The nuclei of these cells also contain the Foxp3 transcription factor that is reported to be a key regulatory gene for the development and function of Treg cells and the most specific marker of this type of cells (Hori et al, 2003; 
Fontenot and Rudensky, 2005). Moreover, IL-2 may affect different cell types, including CD4 $+\mathrm{T}$ cells, NK cells, macrophages and $\mathrm{B}$ cells, resulting in anti-tumour immunity (Jackaman et al, 2003). Interleukin-2 could also activate MCs (Maggiano et al, 1990; Galli et al, 1993), and induce tumour rejection, inhibiting tumour-associated vascularity (Jackaman et al, 2003).

The purpose of this study was to evaluate the effect of IL-2 in the MPM microenvironment and to examine the prognostic value of changes in immunological effector cells and angiogenesis in the group of $60 \mathrm{MPM}$ patients who received preoperative IL-2 treatment.

\section{MATERIALS AND METHODS}

\section{Patients}

A total of 93 patients with MPM were included in this study. The specimens were obtained from patients who underwent surgical resection at the Department of Cardio-Thoracic Surgery of the University of Pisa, from January 1999 to May 2008. Participation in this study required informed consent. No patient had received chemotherapy or radiotherapy before surgery. The patients were divided into two groups: patients who received treatment with preoperative intra-pleural IL-2 and untreated patients. Sixty patients, 51 males and 9 females received preoperative immunotherapy with intra-pleural IL-2 $(18 \times 106$ UI per day every other day for three times), according to eligibility criteria and the treatment protocol described earlier (Lucchi et al, 2007). After 1 day of recovery, the patients underwent a thoracotomy. Of the 60 patients, $53(88.3 \%)$ had a pleurectomy/decortication (P/D), whereas the remaining 7 patients $(11.7 \%)$ had an extrapleural pneumonectomy. Thirty-three patients, 27 men and 6 women underwent surgical resection without preoperative immunotherapy with IL-2 or any other preoperative therapy. All of the 33 patients had a P/D.

\section{Follow-up of IL-2-treated MPM patients}

Sixty patients were observed until death or the final date of analysis (August 2008), with a median follow-up time of 74 months for living patients (range, 2-113 months). Forty-one (68.3\%) patients relapsed during follow-up: 33 had a local relapse, 7 had both a local and a systemic relapse, and only 1 patient had a systemic relapse. At the end of the follow-up period, 15 patients (25\%) were still alive and $45(75 \%)$ had died. Time to progression and overall survival rates were calculated as the period from surgery until the date the disease started to worsen (local and/or systemic recurrences), or date of death (Table 1 ).

\section{Tumour specimens}

All of the tumour samples were formalin-fixed and paraffinembedded for microscopic examination. The most representative paraffin block of tumour was selected for immunohistochemical analysis. A histological and pathological diagnosis were reviewed by two pathologists ( $\mathrm{G}$ Alì and $\mathrm{G}$ Fontanini), according to the WHO 2004 histological and immunohistochemical criteria (Travis et al, 2004). Disagreements concerning the histological diagnosis were discussed, and after a critical discussion, a mutual agreement was reached. The surgical-pathological staging was performed according to the TNM classification by the International Mesothelioma Interest Group (IMIG) (Rusch, 1995).

\section{Immunohistochemistry}

Immunohistochemical analyses were performed on $3 \mu \mathrm{m}$ tissue sections using specific antibodies. Immunoreaction was displayed using the avidin-biotin-peroxidase complex method. Peroxidase
Table I Patients' characteristics: untreatment and treatment related

\begin{tabular}{|c|c|c|}
\hline $\begin{array}{l}\text { Clinicopathologic } \\
\text { characteristics }\end{array}$ & $\begin{array}{l}\text { IL-2-treated patients } \\
(N=60) n . \text { cases }(\%)\end{array}$ & $\begin{array}{l}\text { Untreated patients } \\
(N=33) \text { n. cases (\%) }\end{array}$ \\
\hline \multicolumn{3}{|l|}{ Age } \\
\hline Range & $41-77$ years & $54-81$ years \\
\hline Median & 62.5 years & 70.0 years \\
\hline \multicolumn{3}{|l|}{ Gender } \\
\hline Male & $51(85 \%)$ & $26(78.8 \%)$ \\
\hline Female & $9(15 \%)$ & $7(21.2 \%)$ \\
\hline \multicolumn{3}{|l|}{ Histologic subtypes } \\
\hline Epithelioid & $46(76.7 \%)$ & $25(75.8 \%)$ \\
\hline Biphasic & $9(15.0 \%)$ & $3(9.0 \%)$ \\
\hline Sarcomatoid & $5(8.3 \%)$ & $5(15.2 \%)$ \\
\hline \multicolumn{3}{|l|}{ IMIG stage } \\
\hline IB & | (1.7\%) & \\
\hline ॥ & $15(25.0 \%)$ & $16(48.5 \%)$ \\
\hline III & $44(73.3 \%)$ & $17(51.5 \%)$ \\
\hline \multicolumn{3}{|c|}{ ECOG performance status } \\
\hline 0 & $8(13.3 \%)$ & $6(18.2 \%)$ \\
\hline 1 & $34(56.7 \%)$ & $20(60.6 \%)$ \\
\hline 2 & $18(30.0 \%)$ & $7(21.2 \%)$ \\
\hline \multicolumn{3}{|l|}{ Recurrence (valid n 60) } \\
\hline Yes & 41 & \\
\hline Local & 33 & \\
\hline Local+sistemic & 7 & \\
\hline Sistemic & 1 & \\
\hline No & 19 & \\
\hline \multicolumn{3}{|c|}{ Overall survival (valid n 60) } \\
\hline Range & $2-60$ months & \\
\hline Median & 13 months & \\
\hline \multicolumn{3}{|c|}{ Time to progression (valid n 45) } \\
\hline Range & I -57 months & \\
\hline Median & 12 months & \\
\hline
\end{tabular}

Abbreviations: IMIG = International Mesothelioma interest Group; ECOG = Eastern Cooperative Oncology Group.

activity was visualised with diaminobenzidine. Counterstaining was performed with haematoxylin. The negative controls were carried out by omitting the primary antibodies. Immunostaining was done using a Benchmark immunostainer (Ventana, Tucson, AZ, USA). In all cases, the immunohistochemical evaluation was performed independently by two pathologists ( $G$ Alì and $G$ Fontanini) who were blind to the clinicopathological characteristics and treatment of the patients.

For the tryptase and chymase immunohistochemical stainings, sections were incubated with a mouse anti-human tryptase monoclonal antibody (Chemicon International, Temecula, CA, USA), used at a 1:1500 dilution, and with a mouse anti-human chymase monoclonal antibody (Chemicon International), used at a 1:1600 dilution. Immunostaining for tryptase and chymase was clearly visible as brown deposits within intact MCs and as highly localised extracellular granular material (Figure 1A). Each pathologist identified, under low microscopic power $(\times 10$ objective lens and $\times 10$ ocular lens), the areas where the MCs were the most intensely accumulated, and then counted positive MCs at $\times 200$ microscopic fields. The average of their counts in three fields was calculated as described earlier (Ibaraki et al, 2005).

For TIL-immunohistochemical staining, sections were incubated with the following antibodies: mouse anti-human Foxp3 monoclonal antibody (clone 236A/E7 diluted 1:300; Abcam, Cambridge, UK) (Figure 1B), mouse anti-human CD8 monoclonal antibody 

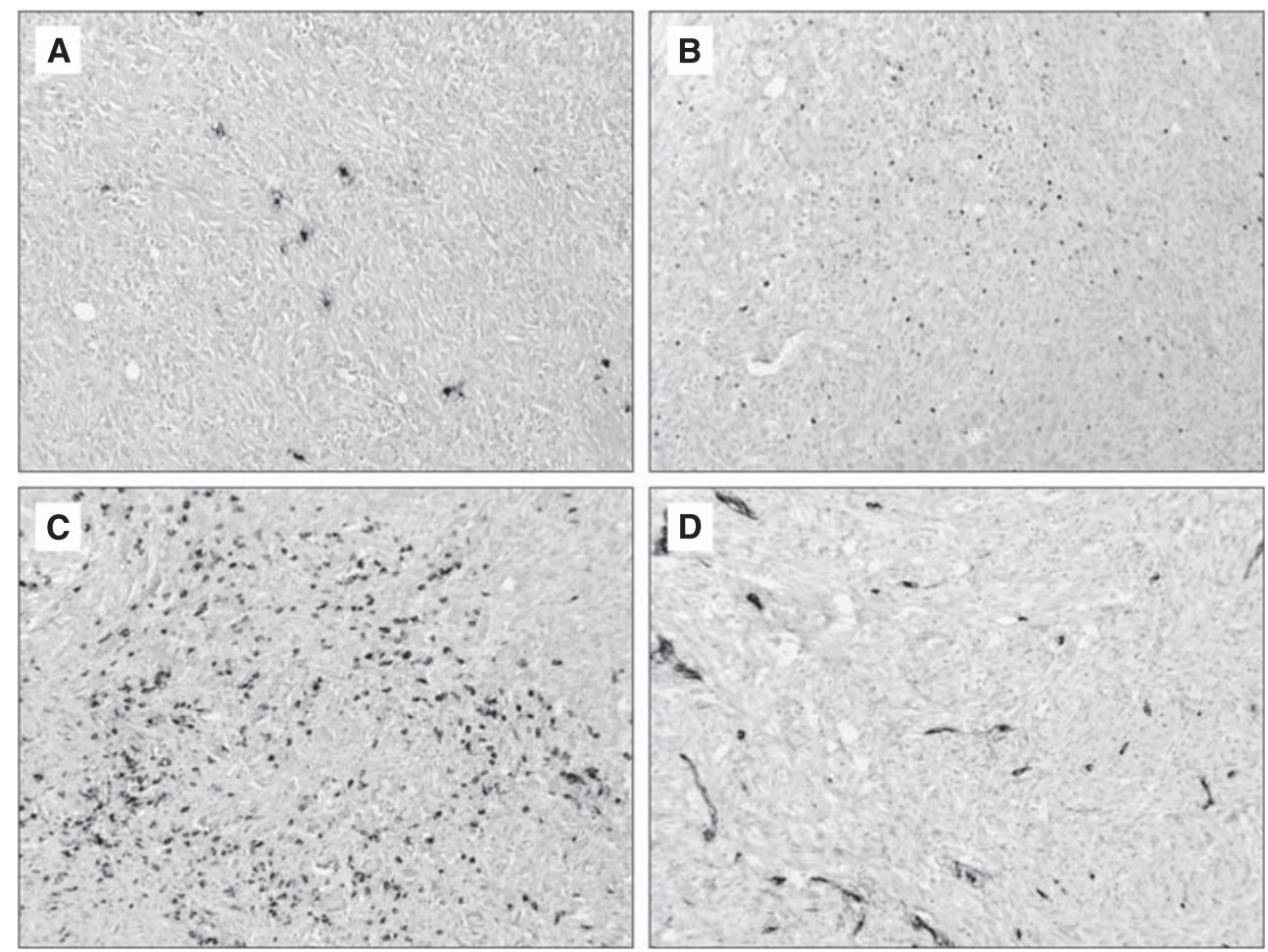

Figure I Immunohistochemical staining for tryptase-positive mast cells microvessel count $(\mathbf{D})$ in mesotheliomas. Original magnification, $\times 100$.

(clone $\mathrm{C} 8 / 144 \mathrm{~B}$, ready to use for the Ventana automated slide stainer; Ventana) (Figure 1C), and mouse anti-human CD4 monoclonal antibody (clone 1F6 diluted 1:20; Diagnostic BioSystem, Pleasanton, CA, USA). Each pathologist identified, under low microscopic power $(\times 25$ objective lens and $\times 10$ ocular lens), the areas where the positive cells were most intensely accumulated, and then counted the cells at $\times 400$ microscopic fields. The average of their counts in five fields was calculated as described earlier (Mizukami et al, 2008; Yoshioka et al, 2008).

The microvessel count (MVC) was determined using the antiCD34 antibody (Ventana Medical System, ready to use for the Ventana automated slide stainer) (Figure 1D). Each pathologist examined the samples and identified the area with the most intense vascularisation (hot spot) under low microscopic power $(\times 10$ objective lens and $\times 10$ ocular lens). In this area, the number of microvessels were counted and recorded at $\times 400(\times 40$ objective lens and $\times 10$ ocular lens).

For the VEGF expression, the sections were incubated with an anti-VEGF rabbit polyclonal antibody (Santa Cruz Biotechnology, Santa Cruz, CA, USA) used at a 1:50 dilution. The expression of VEGF was evaluated as a percentage of positive cells in a total of at least 1000 tumour cells (Ciardiello et al, 2001).

\section{Statistical analysis}

Statistical analysis required the use of the following tests: a Student's $t$-test for the analysis of the differences between preoperative IL-2-treated patients vs untreated patients; an ANOVA to study the association between risk factors and inflammatory and angiogenetic variables; a Kaplan-Meier test to estimate survival function, and a Cox proportional-hazard model for multivariate survival analysis. The analysis was conducted using R 2.9.1. The level of significance was set at a $P$-value of less than 0.05 .
(A), Foxp3-positive lymphocytes (B), CD8-positive lymphocytes (C), and

\section{RESULTS}

\section{Clinicopathological characteristics}

Ninety-three patients were enroled in this study. On the basis of histological features, the tumours were classified as epithelioid in 46 patients $(76.7 \%)$, biphasic in 9 patients $(15 \%)$ and sarcomatoid in 5 patients $(8.3 \%)$ in the group of patients treated with preoperative IL-2. Preoperative intra-pleural IL-2 was administered to all of the patients without a dose reduction or interruption. All of the patients experienced a fever during treatment and required antipyretic medication (acetaminophen). Out of the 33 mesotheliomas belonging to the group of untreated patients, $25(75.8 \%)$ were epithelioid, 3 (9\%) were biphasic and 5 (15.2\%) were sarcomatoid. Other clinicopathological characteristics of the series of patients of both groups are summarised in Table 1.

\section{Analysis of immunological and angiogenetic parameters between the two groups of treatment}

The differences between the two treatment's groups, evaluated by the Student's $t$-test, are summarised in Table 2.

Regarding the MCs, the IL-2-untreated group showed a significantly lower number of the tryptase MCs in comparison with treated patients' group $(P=0.04)$. No differences between the two groups of patients were observed for the chymase MCs.

Immunohistochemistry revealed an increase in the number of $\mathrm{CD} 8+$ lymphocytes in the preoperative-treated group in comparison with the untreated patients $(P=0.004)$. Regarding the $\mathrm{CD} 4+$ lymphocytes, the mean value was higher in the group treated with IL-2 than in the untreated group, but the difference was not statistically significant. Evaluation of Foxp3 + lymphocytes revealed a significant higher number in the treated group compared with the untreated group $(P=0.02)$. 
Table 2 Correlations between immunological and angiogenetic parameters in the IL-2-treated patients' group and in the untreated patients' group

\begin{tabular}{lccl}
\hline $\begin{array}{l}\text { Immunological and } \\
\text { angiogenetic parameters } \\
\text { (mean } \pm \text { s.d.) }\end{array}$ & $\begin{array}{c}\text { IL-2 } \\
\text { treatment }\end{array}$ & $\begin{array}{c}\text { No IL-2 } \\
\text { treatment }\end{array}$ & P-value \\
\hline Tryptase & $26.18 \pm 17.70$ & $19.32 \pm 9.05$ & $\mathbf{0 . 0 4}$ \\
Chymase & $4.06 \pm 5.50$ & $3.40 \pm 5.80$ & 0.60 \\
Foxp3 & $11.80 \pm 12.25$ & $6.12 \pm 9.90$ & $\mathbf{0 . 0 2}$ \\
CD4 & $60.33 \pm 40.38$ & $47.42 \pm 35.00$ & 0.13 \\
CD8 & $90.83 \pm 30.64$ & $67.11 \pm 46.57$ & $\mathbf{0 . 0 0 4}$ \\
CD34 & $62.12 \pm 22.13$ & $147.70 \pm 55.09$ & $\mathbf{0 . 0 0 0}$ \\
VEGF & $33.70 \pm 30.95$ & $38.18 \pm 35.04$ & 0.64 \\
\hline
\end{tabular}

Abbreviation: $\mathrm{IL}=$ interleukin. Bold values indicate $P<0.05$.

As regards MVC, the number of microvessels was significantly lower in the IL-2-treated patients as opposed to untreated patients $(P=0.0001)$. On the contrary, no differences between the two groups of patients were observed for the percentage of VEGF + neoplastic cells.

\section{Associations between immunological and angiogenetic parameters and clinicopathologic characteristics}

Correlations between the analysed parameters and the clinicopathologic characteristics of patients are summarised in Table 3. The MVC was significantly associated with the histologic subtypes of mesothelioma $(P=0.0047)$, with a higher MVC for sarcomatoid and biphasic subtypes than for the epithelioid subtype. No other significant associations were found between the immunological and angiogenetic parameters and the clinicopathological parameters.

\section{Prognostic factors in IL-2-treated MPM patients groups}

In univariate analyses, the histologic subtypes were significantly associated with overall and disease-free survival. The sarcomatoid subtype showed a worse overall survival $(P=0.02)$ and a shorter time-to-progression $(P=0.02)$. No significant association was found between survival and other clinicopathologic parameters (Table 4).

Tryptase-positive MC counts were analysed as a dichotomous variable using the median value to distinguish low $(\leqslant 15)$ from high $(>15)$ MC counts. A statistically significant association was found between the tryptase-positive MC counts and both overall survival $(P=0.02)$ and time-to-progression $(P=0.01)$ (Table 4$)$. A higher tryptase-positive MC count was significantly associated with a better overall survival and a longer time-to-progression (Figure $2 \mathrm{~A}$ and $\mathrm{B}$ ).

The Foxp3 count was also analysed as a dichotomous variable using the median value to distinguish tumours with a low or negative Foxp3 count $(\leqslant 8.2)$ and tumours with a high Foxp3 count $(>8.2)$. Univariate analysis showed that the number of Foxp3 + cells was significantly correlated with overall survival $(P=0.000002)$ and time-to-progression $(P=0.0039)$ (Table 4$).$ In fact, high numbers of Foxp3 + lymphocytes were unfavourable to both survival and recurrence (Figure $2 \mathrm{C}$ and $\mathrm{D}$ ).

To assess whether tryptase-positive MC and Foxp3+ lymphocyte counts in the tumours were independent predictors of survival, a Cox proportional-hazard model was used to carry out multivariate analysis. After stratifying for gender, age, histology, performance status and stage, the two variables maintained their independent prognostic roles (Table 5).
Table 3 Association of immunological and angiogenetic variables with clinicopathologic parameters

\begin{tabular}{lccccccc}
\hline Features & $\begin{array}{c}\text { Tryptase } \\
\text { MCs }\end{array}$ & $\begin{array}{c}\text { Chymase } \\
\text { MCs }\end{array}$ & CD8 & CD4 & Foxp3 & MVC & VEGF \\
\hline $\begin{array}{l}\text { P-values } \\
\text { Age }\end{array}$ & 0.77 & 0.74 & 0.09 & 0.63 & 0.87 & 0.09 & 0.97 \\
Gender & 0.07 & 0.98 & 0.07 & 0.54 & 0.14 & 0.58 & 0.06 \\
IMIG stage & 0.35 & 0.46 & 0.06 & 0.52 & 0.08 & 0.06 & 0.48 \\
Histology & 0.98 & 0.78 & 0.06 & 0.96 & 0.06 & $\mathbf{0 . 0 0 4 7}$ & 0.08 \\
PS & 0.85 & 0.26 & 0.94 & 0.73 & 0.07 & 0.99 & 0.83 \\
\hline
\end{tabular}

Abbreviations: IMIG = International Mesothelioma Interest Group; PS = performance status; $M C s=$ mast cells; $M V C=$ microvessel count. Bold values indicate $P<0.05$.

\section{Combination of tryptase-positive MC and Foxp3 + lymphocyte density}

The prognostic influence of the combination of tryptase-positive MCs and Foxp3 + lymphocytes was then evaluated. Patients were classified into three groups: I $(n=14)$, Foxp3 + lymphocytes high and tryptase-positive MCs low; II $(n=27)$, both high density or both low density; and III $(n=15)$, Foxp3 + lymphocytes low and tryptase-positive MCs high. Significant differences in overall survival were found among the three groups $(P=0.00000017)$ (Figure 2E). Group III has better overall survival than groups II and I.

\section{DISCUSSION}

The tumour-host interaction involves various cell types present in the tumour microenvironment and this interaction could have contradictory effects on tumour progression by either supporting tumour growth or by preventing tumour development (Coussens and Werb, 2002; Mantovani et al, 2008).

IL-2 is a cytokine described to promote activated T-cell proliferation, survival and differentiation (Cantrell and Smith, 1984; Rubin, 1993; Akbar et al, 1996; Armstrong et al, 2001). Reduced levels of IL-2 have been associated with a lower survival of metastatic cancer patients (Herberman, 1984; Lissoni et al, 1991), and numerous trials have been performed using IL-2 alone or in combination with other forms of immunotherapy and chemotherapy (Grande et al, 2006). Several studies have shown an anti-tumoural activity of intra-pleural administration of IL-2 for the treatment of MPM, supporting the use of IL-2 in clinical trials (Goey et al, 1995; Astoul et al, 1998; Castagneto et al, 2001; Mulatero et al, 2001; Lucchi et al, 2007). However, the mechanism underlying the effects of IL-2 in the modification of the MPM microenvironment is still unknown.

In this study, we observed a significant increase of tryptase MCs in IL-2 preoperative-treated patients compared with untreated patients. In a previous study, Maggiano et al (1990) suggested that human MCs express IL-2 receptors on their surface. Furthermore, MCs are known to produce and release different cytokines, including IL-2, promoting the recruitment of immune effector cells (Galli et al, 1993). Other studies (Panelli et al, 2002; Den Otter et al, 2008) suggest that the recruitment of immune cells induced by IL-2 administration at the tumour site could be also because of an indirect affect of IL-2 through MCs activation.

Regarding the TILs, we observed a statistically significant increase in both CD8 and Foxp3 lymphocytes in the IL-2 treatment group. The number of CD4 cells was also increased in the same group, but this finding was not statistically significant. A recent study evaluated various lymphocyte subpopulations after intratumoural administration of IL-2 in a murine model of mesothelioma (Jackaman et al, 2003). The authors showed that IL-2 administration inhibited tumour growth and prolonged survival 
Table 4 Univariate analysis of overall survival and time to progression in MPM patients treated with IL-2

\begin{tabular}{|c|c|c|c|}
\hline Features & $\begin{array}{l}\text { No. of } \\
\text { patients }\end{array}$ & $\begin{array}{l}\text { Overall } \\
\text { survival } \\
P \text {-value }\end{array}$ & $\begin{array}{c}\text { Time to } \\
\text { progression } \\
P \text {-value }\end{array}$ \\
\hline \multicolumn{4}{|c|}{ Age $(41-77$ mean 61.8$)$ median 62.5} \\
\hline$\leqslant 62$ & 30 & & \\
\hline$>62$ & 30 & NS & NS \\
\hline \multicolumn{4}{|l|}{ Gender } \\
\hline Male & 51 & NS & NS \\
\hline Female & 9 & & \\
\hline \multicolumn{4}{|l|}{ IMIG stage } \\
\hline$|\mathrm{B}+| \mid$ & $1+14$ & NS & NS \\
\hline III & 42 & & \\
\hline \multicolumn{4}{|c|}{ Histologic subtypes } \\
\hline Epithelioid & 46 & & \\
\hline Biphasic & 9 & 0.02 & 0.02 \\
\hline Sarcomatoid & 5 & & \\
\hline \multicolumn{4}{|c|}{ ECOG performance status } \\
\hline 0 & 8 & & \\
\hline I & 32 & NS & NS \\
\hline 2 & 17 & & \\
\hline \multicolumn{4}{|l|}{ Tryptase MCs } \\
\hline Low & 16 & 0.02 & 0.01 \\
\hline High & 44 & & \\
\hline \multicolumn{4}{|l|}{ Chymase MCs } \\
\hline Low & 33 & NS & NS \\
\hline High & 27 & & \\
\hline \multicolumn{4}{|l|}{ MVC (CD34) } \\
\hline Low & 30 & NS & NS \\
\hline High & 30 & & \\
\hline \multicolumn{4}{|l|}{ FoxP3 } \\
\hline Low & 29 & 0.000002 & 0.0039 \\
\hline High & 29 & & \\
\hline \multicolumn{4}{|l|}{ CD4 } \\
\hline Low & 24 & NS & NS \\
\hline High & 24 & & \\
\hline \multicolumn{4}{|l|}{ CD8 } \\
\hline Low & 29 & NS & NS \\
\hline High & 28 & & \\
\hline \multicolumn{4}{|l|}{ VEGF } \\
\hline Low & 28 & NS & NS \\
\hline
\end{tabular}

Abbreviations: IMIG = International Mesothelioma Interest Group; ECOG = Eastern Cooperative Oncology Group; $M C s=$ mast cells; $M V C=$ microvessel count; MPM = malignant pleural mesothelioma; NS = not significant. Bold values indicate $P<0.05$.

and that both CD8 and CD4 lymphocytes were required for tumour regression. CD8 T-cells are known have a pivotal role in mediating local tumour immunity throughout antigen-specific tumour cell killing (Zou, 2006). These findings provide a rationale for using IL-2 to enhance CD8 + cytotoxic lymphocyte activity to improve tumoural regression.

Regulatory T (Treg) cells, a subset of CD $4+$ CD25+ Foxp $3+\mathrm{T}$ lymphocytes, are mediators with the functional ability to regulate/suppress tumour immunity (Zou, 2006). High levels of Treg lymphocytes have been observed in malignant tumours (Chattopadhyay et al, 2005) compared to benign lesions and normal tissue (Liyanage et al, 2002; Ichihara et al, 2003; Curiel et al, 2004). In a murine model of mesothelioma (Needham et al., 2006), intra-tumoural recruitment of Treg lymphocytes constituted an immune evasion mechanism leading to an increase in tumour growth. After this, it was proposed that intra-tumoural removal of Treg cells should lead to increased anti-tumour immunity, and various attempts have been made to target Tregs lymphocytes as anti-cancer therapy, with different results (Shimizu et al, 1999; Yu et al, 2005; Hegmans et al, 2006; Needham et al., 2006). The role of IL-2 in mediating Treg cell homeostasis is still unclear, although evidence has suggested a role of IL-2 in promoting the development and suppressive function of Treg cells (Turka and Walsh, 2008). Few studies have explored Treg cells in MPM (DeLong et al, 2005; Hegmans et al, 2006; Anraku et al, 2008). Anraku et al (2008) found a small number of Treg cells in MPM. DeLong et al (2005) also reported a lower number of these cells in the pleural effusions from seven MPM patients, comparing with those from lung or breast cancer patients. On the contrary, Hegmans et al (2006) showed a significant numbers of Treg cells in biopsies from MPM patients, although a small number of cases (only four cases) were analysed. In our study, we observed a significantly higher number of positive Treg cells in the group of IL-2-treated patients compared with untreated patients, confirming the expansion of the Treg subset observed in patients with melanoma and renal carcinoma who underwent IL-2 therapy (Ahmadzadeh and Rosenberg, 2006). Along these lines, the authors showed that the Treg cell population expanded in vitro after IL-2 administration, showing a strong suppressive function of the antitumour immune response. These findings suggest that depletion of the Treg subset lymphocytes may enhance the ability of IL-2 to boost host immunity against cancer.

Several studies have correlated IL-2 therapy with angiogenesis. They show that CD8 lymphocytes seem to be required for reducing tumour-associated vascularity (Sakkoula et al, 1997; Jackaman et al, 2003). In light of these studies, we have also evaluated the MVC and VEGF expression. MVC was significantly lower in IL-2treated patients compared with untreated patients. In the same way, VEGF expression was lower in IL-2-treated patients, but the difference with untreated patients was not significant. Our results support the hypothesis for a role of IL-2 in inhibiting blood vessels in MPM patients, suggesting a supplementary anti-cancer mechanism that is mediated by IL-2 in this type of tumour.

In our study, we found that non-epithelioid subtypes showed a significantly higher MVC than those with epithelioid histology and this finding could be explained by considering that tumours with sarcomatoid differentiation have more aggressive behaviour and poorest prognosis (Travis et al, 2004).

In this study, we confirmed that tryptase-positive MCs predict a better clinical outcome in IL-2-treated patients with MPM (Alì et al, 2009). In the same treatment group, we observed that Treg lymphocytes had a negative impact on the prognosis of patients. As far as we know, this is the first study in which a statistically significant correlation was found between Treg lymphocytes and prognosis in MPM. Anraku et al (2008) found that Treg cells were negatively correlated with prognosis, but the finding was not statistically significant. They also showed that high levels of CD8 + lymphocytes were associated with a better prognosis and with a lower incidence of mediastinal lymph node metastasis. In our study, we observed the same correlation of CD8 + lymphocytes with prognosis in MPM patients treated with IL-2, although it was not statistically significant.

Interestingly, when counts of tryptase-positive MCs and Treg cells are combined, the outcome of patients can be predicted more effectively, confirming the close relationship between these two immunological parameters (Lu et al, 2006; Ju et al, 2009). Therefore, tryptase-positive MCs and Treg lymphocytes are promising prognostic parameters that could be used jointly to identify groups of patients with distinct outcomes. 

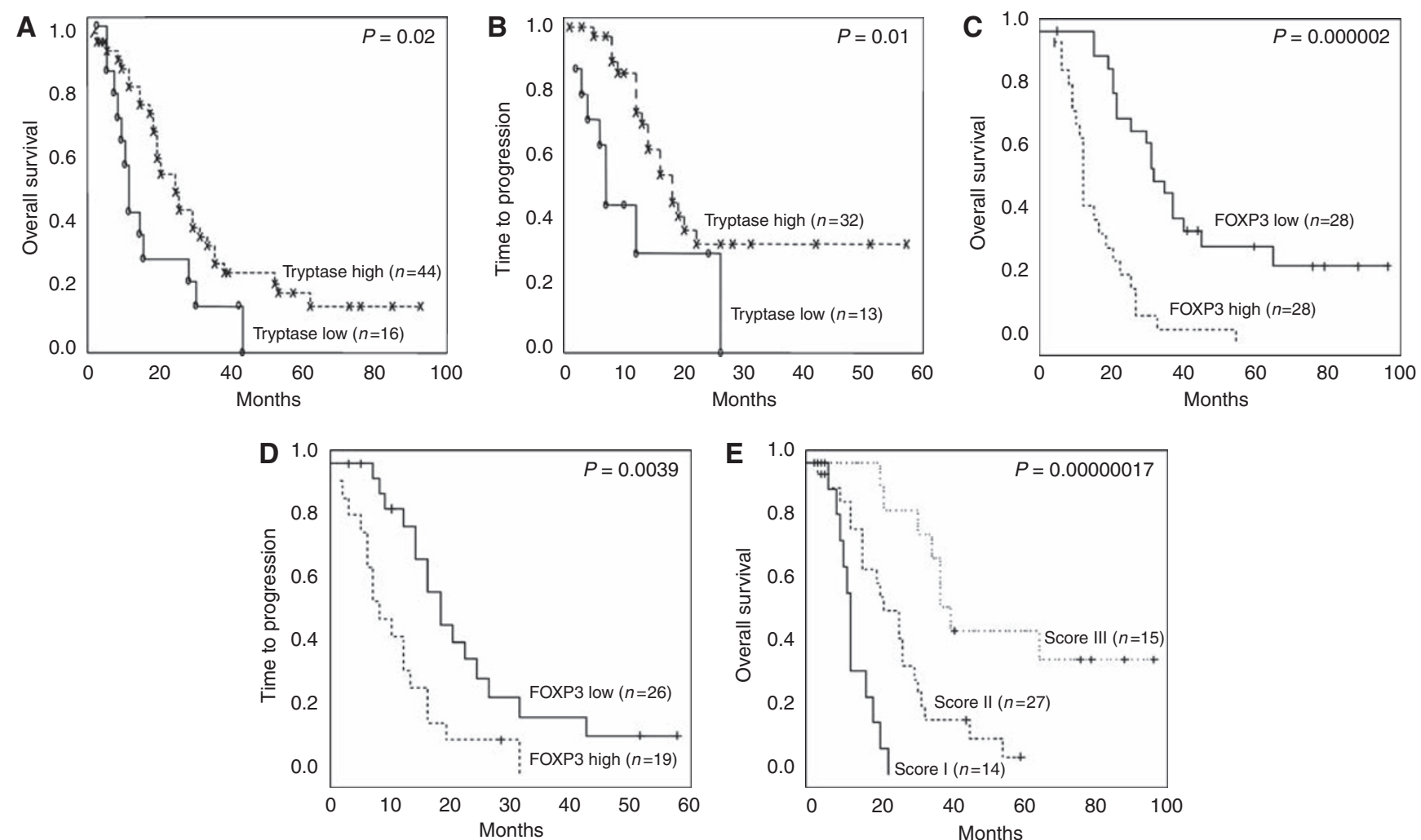

Figure 2 Kaplan-Meier overall survival (A) and time to progression (B) curves for tryptase MCs counts divided into two groups above and below the median value; Kaplan-Meier overall survival $(\mathbf{C})$ and time to progression $(\mathbf{D})$ curves for Foxp3 counts divided into two groups above and below the median value; (E) Kaplan-Meier overall survival curves for combination of tryptase MCs and Foxp3 counts.

Table 5 Multivariate analysis of overall survival according to Cox's model for MPM patients treated with IL-2

\begin{tabular}{lrccrl}
\hline Variables & $\boldsymbol{\beta}$ & $\exp (\boldsymbol{\beta})$ & $\mathbf{s . e .} \exp (\boldsymbol{\beta})$ & \multicolumn{1}{c}{$\mathbf{z}$} & \multicolumn{1}{c}{$\boldsymbol{P}$} \\
\hline Tryptase & -1.054 & 0.348 & 0.351 & -3.005 & $\mathbf{0 . 0 2}$ \\
Foxp3 & 1.974 & 7.201 & 0.410 & 4.812 & $\mathbf{0 . 0 0 0 0 0 1 5}$ \\
Age & -0.002 & 0.998 & 0.021 & -0.114 & 0.910 \\
Gender & 0.256 & 1.292 & 0.565 & 0.454 & 0.650 \\
Histology & -0.668 & 0.513 & 0.699 & -0.955 & 0.340 \\
Stage & 1.411 & 4.098 & 0.450 & 3.135 & 0.067 \\
Performance Status & 1.005 & 2.732 & 0.623 & 1.612 & 0.110 \\
\hline
\end{tabular}

Abbreviation: $M P M=$ malignant pleural mesothelioma. Bold values indicate $P<0.05$.

In conclusion, this study indicates that treatment of MPM with intra-pleural IL-2 leads, on one hand to an increase in tryptase- positive MCs, and in CD8 + and Foxp3 + lymphocytes, and on the other hand to an inhibition in tumour-associated vascularity.

These findings give new insights into the complex anti-tumoural mechanisms mediated by IL- 2 in malignant mesotheliomas, which are useful if IL-2 is to be successfully used in the clinical setting. Further studies are required to confirm the functional properties of the effector, or regulatory phenotypes, as the anti-cancer effect of IL-2 could be related to the correct balance between these two types of immune cells.

Moreover, we propose that counts of tryptase-positive MCs and Treg lymphocytes may be strong predictors of outcome of MPM patients treated with IL-2. These findings underline the importance of the immunologic analysis in the prognostic and therapeutic approach in patients with pleural mesothelioma. New, tailored immunotherapeutic trials in selected patients may be an effective strategy to improve current regimens and prolong survival of this very aggressive and fatal tumour.

\section{REFERENCES}

Ahmadzadeh M, Rosenberg SA (2006) IL-2 administration increases CD4+ CD25+ Foxp3+ regulatory T cells in cancer patients. Blood 107: 2409-2414 Akbar AN, Borthwick NJ, Wickremasinghe RG, Panayoitidis P, Pilling D, Bofill M, Krajewski S, Reed JC, Salmon M (1996) Interleukin-2 receptor common gamma-chain signaling cytokines regulate activated $\mathrm{T}$ cell apoptosis in response to growth factor withdrawal: selective induction of anti-apoptotic (bcl-2, bcl-xL) but not pro-apoptotic (bax, bcl-xS) gene expression. Eur J Immunol 26: 294-299

Alì G, Boldrini L, Lucchi M, Mussi A, Corsi V, Fontanini G (2009) Tryptase mast cells in malignant pleural mesothelioma as an independent favorable prognostic factor. J Thorac Oncol 4: 348-354
Anraku M, Cunningham KS, Yun Z, Tsao MS, Zhang L, Keshavjee S, Johnston MR, de Perrot M (2008) Impact of tumor-infiltrating T cells on survival in patients with malignant pleural mesothelioma. $J$ Thorac Cardiovasc Surg 135: 823-829

Armstrong AC, Eaton D, Ewing JC (2001) Science, medicine, and the future: cellular immunotherapy for cancer. BMJ 323: 1289-1293

Astoul P, Picat-Joossen D, Viallat J-R, Boutin C (1998) Intrapleural administration of interleukin-2 for the treatment of patients with malignant pleural mesothelioma. A phase II study. Cancer 83: 2099-2104 Balkwill F, Mantovani A (2001) Inflammation and cancer: back to Virchow? Lancet 357: $539-545$ 
Cantrell DA, Smith KA (1984) The interleukin-2 T-cell system: a new cell growth model. Science 224: $1312-1316$

Castagneto B, Zai S, Mutti L, Lazzaro A, Ridolfi R, Piccolini E, Ardizzoni A, Fumagalli L, Valsuani G, Botta M (2001) Palliative and therapeutic activity of IL-2 immunotherapy in unresectable malignant pleural mesothelioma with pleural effusion: results of a phase II study on 31 consecutive patients. Lung Cancer 31: 303-310

Chattopadhyay S, Chakraborty NG, Mukherji B (2005) Regulatory T cells and tumor immunity. Cancer Immunol Immunother 54: 1153-1161

Ciardiello F, Caputo R, Bianco R, Damiano V, Fontanini G, Cuccato S, De Placido S, Bianco AR, Tortora G (2001) Inhibition of growth factor production and angiogenesis in human cancer cells by ZD1839 (Iressa), a selective epidermal growth factor receptor tyrosine kinase inhibitor. Clin Cancer Res 7: 1459-1465

Coussens LM, Werb Z (2002) Inflammation and cancer. Nature 420: 860 - 867

Curiel TJ, Coukos G, Zou L, Alvarez X, Cheng P, Mottram P, EvdemonHogan M, Conejo-Garcia JR, Zhang L, Burow M, Zhu Y, Wei S, Kryczek I, Daniel B, Gordon A, Myers L, Lackner A, Disis ML, Knutson KL, Chen L, Zou W (2004) Specific recruitment of regulatory $\mathrm{T}$ cells in ovarian carcinoma fosters immune privilege and predicts reduced survival. Nat Med 10: $942-949$

DeLong P, Carroll RG, Henry AC, Tanaka T, Ahmad S, Leibowitz MS, Sterman DH, June CH, Albelda SM, Vonderheide RH (2005) Regulatory T cells and cytokines in malignant pleural effusions secondary to mesothelioma and carcinoma. Cancer Biol Ther 4: 342-346

Den Otter W, Jacobs JJ, Battermann JJ, Hordijk GJ, Krastev Z, Moiseeva EV, Stewart RJ, Ziekman PG, Koten JW (2008) Local therapy of cancer with free IL-2. Cancer Immunol Immunother 57: 931 - 950

Fontenot JD, Rudensky AY (2005) A well adapted regulatory contrivance: regulatory $\mathrm{T}$ cell development and the forkhead family transcription factor Foxp3. Nat Immunol 6: 331-337

Galli SJ, Gordon JR, Wershil BK (1993) Mast cell cytokines in allergy and inflammation. Agents Actions Suppl 43: 209-220

Goey SH, Eggermont AM, Punt CJ, Slingerland R, Gratama JW, Oosterom R, Oskam R, Bolhuis RL, Stoter G (1995) Intrapleural administration of interleukin 2 in pleural mesothelioma: a phase I-II study. Br J Cancer 72: $1283-1288$

Grande C, Firvida JL, Navas V, Casal J (2006) Interleukin-2 for the treatment of solid tumors other than melanoma and renal cell carcinoma. Anticancer Drugs 17: 1 - 12

Herberman RB (1984) Summary: potential of interleukin-2 for the therapy of cancer. J Biol Response Mod 3: 527-532

Hegmans JP, Hemmes A, Hammad H, Boon L, Hoogsteden HC, Lambrecht BN (2006) Mesothelioma environment comprises cytokines and T-regulatory cells that suppress immune responses. Eur Respir $J$ 27: $1086-1095$

Hori S, Nomura T, Sakaguchi S (2003) Control of regulatory T cell development by the transcription factor Foxp3. Science 299: 1030-1031

Ibaraki T, Muramatsu M, Takai S, Jin D, Maruyama H, Orino T, Katsumata T, Miyazaki M (2005) The relationship of tryptase- and chymase-positive mast cells to angiogenesis in stage I non-small cell lung cancer. Eur J Cardiothorac Surg 28: 617-621

Ichihara F, Kono K, Takahashi A, Kawaida H, Sugai H, Fujii H (2003) Increased populations of regulatory $\mathrm{T}$ cells in peripheral blood and tumor-infiltrating lymphocytes in patients with gastric and esophageal cancers. Clin Cancer Res 9: 4404-4408

Jackaman C, Bundell CS, Kinnear BF, Smith AM, Filion P, van Hagen D, Robinson BW, Nelson DJ (2003) IL-2 intratumoral immunotherapy enhances $\mathrm{CD} 8+\mathrm{T}$ cells that mediate destruction of tumor cells and tumor-associated vasculature: a novel mechanism for IL-2. J Immunol 171: $5051-5063$

Ju MJ, Qiu SJ, Gao Q, Fan J, Cai MY, Li YW, Tang ZY (2009) Combination of peritumoral mast cells and T-regulatory cells predicts prognosis of hepatocellular carcinoma. Cancer Sci 100: 1267-1274

Lissoni P, Barni S, Rovelli F, Tancini G (1991) Lower survival in metastatic cancer patients with reduced interleukin-2 blood concentrations. Preliminary report. Oncology 48: 125-127

Liyanage UK, Moore TT, Joo HG, Tanaka Y, Herrmann V, Doherty G, Drebin JA, Strasberg SM, Eberlein TJ, Goedegebuure PS, Linehan DC
(2002) Prevalence of regulatory T cells is increased in peripheral blood and tumor microenvironment of patients with pancreas or breast adenocarcinoma. J Immunol 169: 2756-2761

Lu LF, Lind EF, Gondek DC, Bennett KA, Gleeson MW, Pino-Lagos K, Scott ZA, Coyle AJ, Reed JL, Van Snick J, Strom TB, Zheng XX, Noelle RJ (2006) Mast cells are essential intermediaries in regulatory T-cell tolerance. Nature 442: $997-1002$

Lucchi M, Chella A, Melfi F, Dini P, Tibaldi C, Fontanini G, Mussi A (2007) Four-modality therapy in malignant pleural mesothelioma: a phase II study. J Thorac Oncol 2: 237-242

Maggiano N, Colotta F, Castellino F, Ricci R, Valitutti S, Larocca LM, Musiani P. (1990) Interleukin-2 receptor expression in human mast cells and basophils. Int Arch Allergy Appl Immunol 91: 8-14

Mantovani A, Romero P, Palucka AK, Marincola FM (2008) Tumour immunity: effector response to tumour and role of the microenvironment. Lancet 371: 771-783

Mizukami Y, Kono K, Kawaguchi Y, Akaike H, Kamimura K, Sugai H, Fujii $\mathrm{H}$ (2008) Localisation pattern of Foxp3+ regulatory T cells is associated with clinical behaviour in gastric cancer. Br J Cancer 98: 148-153

Mulatero CW, Penson RT, Papamichael D, Gower NH, Evans M, Rudd RM (2001) A phase II study of combined intravenous and subcutaneous interleukin-2 in malignant pleural mesothelioma. Lung Cancer 31: 67-72

Needham DJ, Lee JX, Beilharz MW (2006) Intra-tumoural regulatory T cells: a potential new target in cancer immunotherapy. Biochem Biophys Res Commun 343: 684-691

Panelli MC, Wang E, Phan G, Puhlmann M, Miller L, Ohnmacht GA, Klein HG, Marincola FM (2002) Gene-expression profiling of the response of peripheral blood mononuclear cells and melanoma metastases to systemic IL-2 administration. Genome Biol 3: 1-17

Robinson BW, Musk AW, Lake RA (2005) Malignant mesothelioma. Lancet 366: $397-408$

Rubin JT (1993) Interleukin-2: its biology and clinical application in patients with cancer. Cancer Invest 11: 460-472

Rusch VW (1995) A proposed new international TNM staging system for malignant pleural mesothelioma. From the International Mesothelioma Interest Group. Chest 108: 1122-1128

Rusch VW, Rosenzweig K, Venkatraman E, Leon L, Raben A, Harrison L, Bains MS, Downey RJ, Ginsberg RJ (2001) A phase II trial of surgical resection and adjuvant high-dose hemithoracic radiation for malignant pleural mesothelioma. J Thorac Cardiovasc Surg 122: 788-795

Sakaguchi S, Toda M, Asano M, Itoh M, Morse SS, Sakaguchi N (1996) T cell-mediated maintenance of natural self-tolerance: its breakdown as a possible cause of various autoimmune diseases. J Autoimmun 9: 211-220

Sakkoula E, Pipili-Synetos E, Maragoudakis ME (1997) Involvement of nitric oxide in the inhibition of angiogenesis by interleukin-2. $\mathrm{Br} J$ Pharmacol 122: 793 -795

Shimizu J, Yamazaki S, Sakaguchi S (1999) Induction of tumor immunity by removing $\mathrm{CD} 25+\mathrm{CD} 4+\mathrm{T}$ cells: a common basis between tumor immunity and autoimmunity. J Immunol 163: 5211-5218

Travis WD, Brambilla E, Müller-Hermelink HK, Harris CC (2004) World Health Organization Classification of Tumours. Pathology and Genetics of Tumours of the Lung, Pleura, Thymus and Heart. IARC Press: Lyon, France

Turka LA, Walsh PT (2008) IL-2 signaling and CD4+ CD25+ Foxp3+ regulatory T cells. Front Biosci 13: $1440-1446$

Yoshioka T, Miyamoto M, Cho Y, Ishikawa K, Tsuchikawa T, Kadoya M, Li L, Mishra R, Ichinokawa K, Shoji Y, Matsumura Y, Shichinohe T, Hirano S, Shinohara $\mathrm{T}$, Itoh $\mathrm{T}$, Kondo $\mathrm{S}$ (2008) Infiltrating regulatory $\mathrm{T}$ cell numbers is not a factor to predict patient's survival in oesophageal squamous cell carcinoma. Br J Cancer 98: 1258 - 1263

Yu P, Fu YX (2006) Tumor-infiltrating T lymphocytes: friends or foes? Lab Invest 86: $231-245$

Yu P, Lee Y, Liu W, Krausz T, Chong A, Schreiber H, Fu YX (2005) Intratumor depletion of CD4+ cells unmasks tumor immunogenicity leading to the rejection of late-stage tumors. J Exp Med 201: 779-791

Zou W (2005) Immunosuppressive networks in the tumour environment and their therapeutic relevance. Nat Rev Cancer 5: 263-274

Zou W (2006) Regulatory T cells, tumour immunity and immunotherapy. Nat Rev Immunol 6: 295-307 